\title{
Production and Utilization of L-Arabinose in China
}

\section{Biao Hu1,2, Haiyang Li³, Qingfu Wang1, Yicong Tan4, Ruirong Chen1, Jingrong Li1, Wenting Ban', Lei Liang1,5*}

${ }^{1}$ Guangdong Provincial Bioengineering Institute (Guangzhou Sugarcane Industry Research Institute), Guangzhou, China

${ }^{2}$ Guangdong Provincial Key Laboratory of Sugarcane Improvement and Biorefinery, Guangzhou, China

${ }^{3}$ Department of Neurology, The Third Affiliated Hospital of Sun Yat-sen University, Guangzhou, China

${ }^{4}$ YingdeYuebei Sugar Industry Co., Ltd., Guangzhou, China

${ }^{5}$ Guangzhou Key Laboratory of Biomass Comprehensive Utilization, Guangzhou, China

Email: ${ }^{252897555 @ q q . c o m ~}$

How to cite this paper: $\mathrm{Hu}, \mathrm{B}$., Li, H.Y., Wang, Q.F., Tan, Y.C., Chen, R.R., Li, J.R., Ban, W.T. and Liang, L. (2018) Production and Utilization of L-Arabinose in China. World Journal of Engineering and Technology, 6, 24-36.

https://doi.org/10.4236/wjet.2018.63B004

Received: May 8, 2018

Accepted: August 6, 2018

Published: August 9, 2018

\begin{abstract}
L-arabinose is a newly developed low-caloric monosaccharide, which has many biomedical and health effects, especially intestinal sucrase inhibition effect. L-arabinose is mainly produced by chemical or enzymatic hydrolysis of hemicellulose. The taste of L-arabinose is quite similar to that of sucrose, with approximately $50 \%$ of the sweetness. As a functional additive, L-arabinose can be used in medical and pharmaceutical applications for the treatment of diseases such as diabetes, chronic constipation, mineral absorption disorder and secondary bile acid formation disorder. However, L-arabinose has not been widely used in functional foods due to high price and lack of publicity and guidance. A comprehensive review of L-arabinose physicochemical properties, production, applications field, market statue and development direction is presented in this paper.
\end{abstract}

\section{Keywords}

L-Arabinose, Application Fields, Market Statue, Development Direction

\section{Introduction}

The main sweeteners in China's food are sucrose, starch sugars, artificial or natural high-intensity sweeteners, glucose, fructose, and sugar alcohols at present. Among them, sucrose is the most used sweetener, with an annual sales volume of 10 million tons and a sales price of $6100-6500$ yuan per ton [1]. Sucrose, glucose and other products have a high glycemic index. Excess intake of such 
sweeteners can easily lead to excess energy in the body, causing tooth decay, obesity, diabetes, and cardiovascular disease. Therefore, the development of new varieties of sweeteners can not only maintain a good sweetness of food, but also reduce the risk of high blood sugar, high blood lipids and other diseases, and is currently a hot issue in the nutrition, medicine, and food industries.

L-arabinose is a newly developed low-caloric monosaccharide, which has many biomedical and health effects, especially intestinal sucrase inhibition effect. As a low-calorie sweetener [2] [3], L-arabinose has been approved by the American Medical Society and Japanese Ministry of Health to be used as an anti-obesity agent, nutritional supplements or prescription drugs. L-arabinose has been approved as a new resource food by Ministry of Health of China in 2008, which can be used in all foods except infant foods [4]. However, L-arabinose has not been widely used in functional foods due to high price and lack of publicity. L-arabinose is also widely used in medical field, chemistry, and biological fields as a kind of important chemical products.

\section{Physicochemical Property and Existence of L-Arabinose in the Nature}

\subsection{Physicochemical Property of L-Arabinose}

$\mathrm{L}$-arabinose $(\mathrm{C} 5 \mathrm{H} 10 \mathrm{O} 5, \mathrm{Mr}=150.13)$, an aldopentose, is initially isolated from arabic gum via complex chemical and physical methods [5] [6]. L-arabinose is an odorless white needle-like crystalline at room temperature, and it is soluble in water, slightly soluble in alcohol, insoluble in ether, methanol and acetone. Some property of L-arabinose: Melting point: $154^{\circ} \mathrm{C}-158^{\circ} \mathrm{C}$, Specific rotation $[\alpha] 20 \mathrm{D}$ $\left(\mathrm{H}_{2} \mathrm{O}, 24 \mathrm{~h}\right)+100 \sim+104^{\circ}$, relative density 1.585 [4] [7]. The sweetness of $\mathrm{L}$-arabinose is about half of sucrose.

Linear form of L-arabinose is having a carbonyl group $(\mathrm{C} 1)$ at the top of the carbon chain. The C-5 linked oxygen atom of 1.1 carries out nucleophilic attack on the carbonyl to give a cyclic structure 1.2, which forms $\beta$-L-arabinose 1.3 and $\alpha$-L-arabinose 1.4 epimers due to the different spatial arrangement of the newly formed chiral C-1 atom (Figure 1).

\subsection{Existence of L-Arabinose in the Nature}

Free L-arabinose rarely exists in the nature, it only been found in the core of coniferous trees [8]. As a component of heteropolysaccharides that is found in gum, hemicellulose, bacterial polysaccharides and some glycoside, L-arabinose exists in the form of $\beta$-L-arabinose. Figure 2 (a) shows the presence of L-arabinose in corn cob hemicellulose: the backbone is $\beta$-1,4-conjugated D-xylan, which can be combined with the hemiacetal hydroxyl of L-arabinose in the side chain at both the 2 and 3 positions of the xylose residue. Typically, more than $61 \%$ of L-arabinose is present at the non-reducing end [9]. However, L-arabinose exists mostly in the form of L-arabinose-oligosaccharides in sugar beet pectin: L-arabinose oligosaccharides (with a degree of polymerization of 10 - 20 in multiple forms and shapes) combined with the backbone of the pectin 


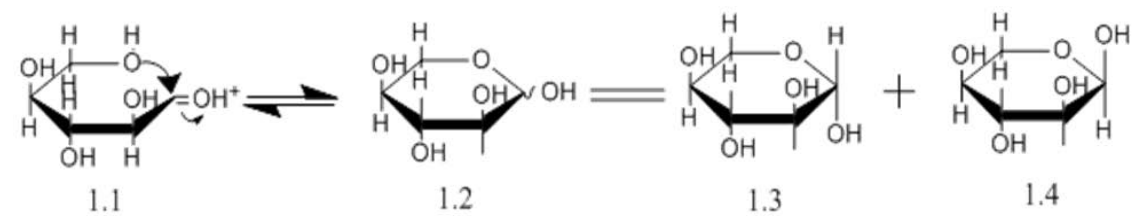

Figure 1. Transition of L-arabinose from linearity to circularity.

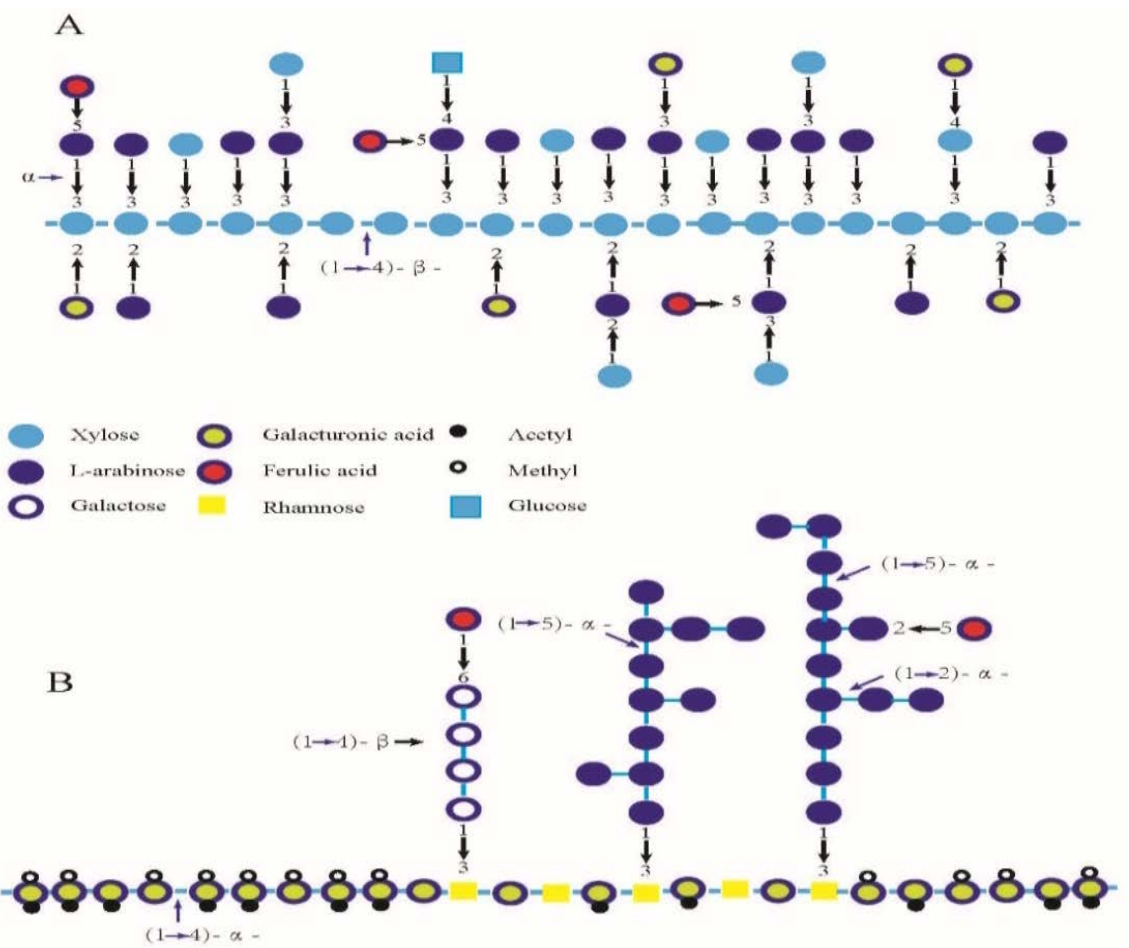

Figure 2. Structure of hemicellulose: (a) Structure of maize hemicellulose modified from L. saulnier, (b) Structure of sugar beet pectin modified from A. voragen.

that consisted by D-galacturonic acid and rhamnose both at the 3 or 4 positions of the rhamnoseresidue [10] [11] (Figure 2(b)).

\section{L-Arabinose Production}

\subsection{Production Statue of L-Arabinose}

As a newly developed functional sugar, L-arabinose generally produced by hydrolysis of biomass that rich in L-arabinose residue such as vegetable gums [5] [12], corncob [13] [14], beet pulp [15], bagasse [16] and other materials [17]. L-arabinose can also prepared by chemical or biological synthesis methods, but both methods have shortcomings of high costs, difficult to separate, so it is rarely used in commercial production [18].

Domestic enterprises with a certain scale mainly include: Jinan healtang Biotech Co., Ltd., Xiamen Thomson Biotech Co., Ltd., Shandong Futase Co., Ltd., Jilin Huakang Pharmaceutical, Danisco (China) Co., Ltd., and Shandong Longlive Biotech Co., Ltd., Shandong Tanglikang Co., Ltd. Among them, Jinan Healtang Biotech Co., Ltd. is the largest producer of L-arabinose sugar in China 
which has the world's first 1000 ton production device.

As a new functional sweetener, L-arabinose has huge market space in people with diabetes, obesity, and health care food products. With the improvement of people's awareness, and deepening of research, L-arabinose will be more widely used in the fields of food industry, medicine and cosmetics, it will make a greater contribution in promoting human health and improving people's life quality.

\subsection{Problems Exist in L-Arabinose Production}

L-arabinose can be prepared by enzymatic hydrolysis of hemicellulose, chemical synthesis, and biotransformation. However, certain problems exist in those methods.

1) Acid hydrolysis of corn bran, sugar cane pulp and other high L-arabinose content biomass: this method includes alkaline extraction and acid hydrolysis of Arabinoxylan. it is the most mature method with relative high yields, however obvious drawbacks also exists: (1) harmful substances generates in high alkaline concentration and extraction temperature environment; (2) a lot of salts generated in neutralization process makes subsequent crystallization process more complex, consumes more energy and time leading to higher production costs; (3) large-scale use of strong base and acid not only cause corrosion of equipment, but also has the potential of polluting the environment since a large amount of industrial waste is produced.

2) Acid hydrolysis of Arabic gum: the mixture of L-arabinose, xylose, rhamnose, galactose and other monosaccharides is obtained by acid hydrolysis of Gum Arabic. After the mixture is neutralized, yeast fermentation is used to remove fermented carbohydrates (such as galactose and glucose). It was then crystallized in methanol to give crude L-arabinose which was subsequently recrystallized from $90 \%$ ethanol to give pure L-arabinose crystal that approximately have a yield of $15.6 \%$ and $97.5 \%$ purity.

This way also exists some drawbacks: (1) large-scale use of acid not only cause corrosion of equipment, but also has the potential of polluting the environment since a large amount of salts is produced. (2) Yeast fermentation process is the most time and energy consuming step in the whole process as sterilization (consumes large amount of energy), yeast growth and consumes fermented carbohydrates (needs more than $24 \mathrm{~h}$ ) is required, leading to lower productivity and higher production costs. (3) It is costly to use gum arabic to produce L-arabinose since gum arabic itself is in low production and high price.

3) Enzyme hydrolysis of high L-arabinose content biomass: this method effectively integrates the above two methods and avoids its' disadvantages. It is a more practical, environmental protection and efficient way. This method uses cellulase and arabinoxylanse to hydrolyze high L-arabinose content biomass and the hydrolysate is then fermented by yeast to get rid of fermented carbohydrates. The method has the advantages of mild reaction conditions, strong specificity, and simple purification steps. The problem with this method is that the activity 
of cellulase or arabinoxylanase is not high and the hydrolysis time is relatively long, and the price of cellulase or arabinoxylanase is too high compared to hydrochloric acid and sulfuric acid, resulting in higher investment cost.

4) Chemical or biological synthesis of L-arabinose: L-arabinose can also be prepared by chemical synthesis or biotransformation. For example, through a series of addition reaction, ring opening, dehydrogenation and other steps, L-arabinose is obtained from dihydropyran. L-arabinose can also be obtained from L-ribose catalyzed by L-arabinose isomerase, while the L-ribose is obtained from L-ribitol catalyzed by acetobacter. A variety of optical isomers is produced no matter by chemical synthesis or biotransformation resulting in low production efficiency and high production costs, this is because separation and purification of optical isomers remains the bottleneck of global industrial crystallization separation.

\section{Physiological Activity of L-Arabinose}

As a newly developed functional sugar, L-arabinose mainly has the following features.

\subsection{Specifically Inhibition Effect on Sucrase ( $\alpha$-Glucosidase) Activity}

Compared with the other functional sugar, the representative physiological activity of L-arabinose is that it specifically inhibits intestine sucrase activity, thereby inhibiting the hydrolysis and sbsorption of sucrose, and reducing the magnitude of hyperglycemia. G. Semenza [19] found that the rabbit intestinal sucrase can be non-competitive inhibited by L-arabinose in both $10 \mathrm{mM}$ and 50 $\mathrm{mM}$ concentration, with the inhibition rate $65 \%$ and $80 \%$, respectively.

Researches revealed that only L-arabinose can non-competitive inhibit intestinal mucosa sucrase activity, while the $\mathrm{D}$-arabinose or L-arabinbiose had no such activity, and the binding constant of L-arabinose with sucrase is 12 times that of sucrose with sucrase. At the same time, L-Arabinose has no significant inhibition effect on pancreas amylase, intestinal mucosa maltase, isomaltase, trehalase, lactase [2] [20] [21].

\subsection{Hypolipidemic and Hypoglycemic Effect}

L-arabinose has hypolipidemic and hypoglycemic effect which can prevent effectively from some metabolic diseases, such as obesity, diabetes. The intervention experiment of $\mathrm{L}$-arabinose on high fat and high fat feeding rats and mice shows that L-arabinose can significantly reduce the fasting blood glucose, enhance glucose tolerance, and can effectively slow the growth of weight, compared with the control group [22] [23].

Han [24] confirmed that L-arabinose can reduce the fat index, inhibit and eliminate the accumulation of fat, thus to achieve the effect of weight loss on high fat and high fat feeding rabbits. Liu [3] and Shibanuma [25] tested the ef- 
fects of L-arabinose on adults postprandial glucose levels and body weight index. Results shown that 1) the postprandial glycemic index of the experimental group supplemented with $\geq 3 \%$ of L-arabinose were significantly lower than that of the control group after 30 days in the postprandial blood glucose test; 2) compared with the normal diet obese group, the intervention group supplemented with $\geq$ $5 \%$ of L-arabinose (20 obese subjects) average decreased $5.5 \mathrm{~kg}$ after 6 months, indicating that $\mathrm{L}$-arabinose significantly reduce postprandial glycemic index and has a slimming effect.

\subsection{Promote Bifidobacterium Proliferation and Regulate Intestinal Balance}

Research shows that the L-arabinose content in the various dietary fiber residue decreases significantly when it go through rat or human digestive tract, in where $\mathrm{L}$-arabinose is dissolved and absorbed as a monosaccharide or oligosaccharide and then used by intestinal bacteria [26].

This is because $\mathrm{L}$-arabinose residue is mainly present at the non-reducing end of the side chain (Figure 2(a)), which easily hydrolysis to free sugars in the acid environment of the stomach and then implement the functional characteristics of inhibition of blood glucose elevation, reduction of serum neutral fat and cholesterol concentration, proliferation of intestinal bifidobacteria, and so on. Studies show that L-arabinose promotes the growth of bifidobacteria thereby enhancing the body's immune system and control weight gain in mice [27]. To the other hand, L-arabinose itself is difficult to be absorbed and utilized to generate energy in the body and the non-utilized part can be excreted from the urine so it will not lead to obesity.

\subsection{Change of Skeletal Muscle Composition}

Skeletal muscle is the place using sugar and insulin, change of skeletal muscle composition affects the insulin sensitivity. Research shows that the number of type I muscle fibers increases significantly while type II muscle fibers decreases after long-term utilization of L-arabinose, so taking L-arabinose can ameliorate type 2 diabetes mellitus symptoms since type I muscle fibers effectively improve insulin resistance [23] [28] [29].

\section{Applications of L-Arabinose}

Having the effects of low calorie value, specifically inhibit intestine sucrase activity, proliferation of intestinal bifidobacteria and other characteristics, L-arabinose is widely used in the food processing industry, chemistry, and biological fields as an important chemical products (Table 1).

L-arabinose is white powdery crystal under normal temperature and pressure, it is odorless and easily soluble in water. L-arabinose's taste is similar to that of sucrose with about $50 \%$ of sucrose sweetness, it can be used as a sucrose alternatives. As it can specifically inhibit sucrose activity and regulate intestinal balance, 
Table 1. Overview of the L-arabinose applications.

\begin{tabular}{|c|c|c|}
\hline Fields & Directions & Notes \\
\hline \multirow[t]{4}{*}{$\begin{array}{l}\text { Food } \\
\text { Processing }\end{array}$} & Table sugar [30] [31] & $\begin{array}{l}\text { Taste similar to sucrose, } 50 \% \text { of sucrose sweetness, ready used } \\
\text { as table sugar. }\end{array}$ \\
\hline & $\begin{array}{l}\text { Functional food [32] } \\
{[33]}\end{array}$ & $\begin{array}{l}\text { Special health food additive for regulating blood sugar, used in } \\
\text { diabetic foods, diet foods, and other functional foods. }\end{array}$ \\
\hline & Beverage [34] [35] & $\begin{array}{l}\text { Can be added to functional drinks such as low sugar drinks, } \\
\text { sugar-free drinks, tea drinks, milk drinks, vegetable protein } \\
\text { drinks, fruit-vegetable juice drinks. It can also be used in spirit } \\
\text { or wine to alleviate hangover. }\end{array}$ \\
\hline & Bake [36] [37] & $\begin{array}{l}\text { L-Arabinose has a relatively stable structure and does not } \\
\text { decompose at high temperatures. The Maillard reaction during } \\
\text { baking makes the flavor of bakery products more unique and } \\
\text { brighter. }\end{array}$ \\
\hline \multirow[t]{2}{*}{$\begin{array}{l}\text { Biopharma- } \\
\text { ceutical }\end{array}$} & $\begin{array}{l}\text { Rare sugar synthesis } \\
\text { [38] [39] [40] }\end{array}$ & $\begin{array}{l}\text { Substances for example L-ribose, L-ribulose, D-tagatose, } \\
\text { L-arabinitol, and C-nucleosides were prepared by biological } \\
\text { fermentation, chemical synthesis based on L-arabinose. }\end{array}$ \\
\hline & $\begin{array}{l}\text { pharmaceutical [41] } \\
{[42][43]}\end{array}$ & $\begin{array}{l}\text { Arabinose is an important pharmaceutical intermediate that } \\
\text { not only can be used to synthesize cytarabine, L-arabinoside, } \\
\text { L-ribose, deoxyribose, but also can be used to synthesize } \\
\text { nucleoside antiviral drugs. }\end{array}$ \\
\hline \multirow[t]{2}{*}{ Others } & Energy [44] [45] & $\begin{array}{l}\text { Strains that capable of producing energy substances such as } \\
\text { ethanol and butanol using L-arabinose are obtained through } \\
\text { domestication and genetic recombination. }\end{array}$ \\
\hline & $\begin{array}{l}\text { Fine chemicals [46] } \\
{[47]}\end{array}$ & Preparation of surfactants, metal-carbohydrate complexes. \\
\hline
\end{tabular}

L-arabinose can be used as a functional food addictive for alleviating hypertension, hyperglycemia, hyperlipemia. As L-arabinose has fine food compatibility, it can be used in beverage products, candy, baked foods. L-arabinose can help solve "frosting" of chocolate and "sandy" of candy. As a reducing monosaccharide, L-arabinose contains an aldehyde group, which reacts with the amino acids, proteins and other substances (Maillard browning reaction) to form unique flavor and more bright color in the preparation of baked foods.

L-arabinose can be used as a non-prescription drugs as an anti-obesity nutritional supplements, or as a medicine pharmaceutical excipients and filling agents for syrups and tablets since it is difficult to be absorbed and utilized to generate energy in the body and the non-utilized part can be excreted from the urine.

L-arabinose can also be used for the synthesis of important pharmaceutical intermediates. Five anti-hepatitis B drugs entered into the Phase three clinical trials globally in 2010-2014, two of which uses L-arabinose as raw material, namely Clevudine (L-FMAU) of the Korean Bukwang Pharmaceuticals and Telbivudine of the United States Idenix Pharmaceuticals. These two drugs able to specifically inhibit the hepatotropic DNA viruses without an impact on the DNA polymerase and mitochondrial function, currently it has been widely used in the clinical treatment of hepatitis B.

L-arabinose is an ideal synthesis intermediates for flavors: study shown that 
flavor synthesized from L-arabinose has a soft, rich aroma, which is more natural and plump aroma. An increasing number of foreign flavor companies are trying to use L-arabinose in the production of Synthetic essence.

A new metal-organic frame thus calcium-L-arabinose complexes has been synthesized and characterized using L-arabinose as a raw material. Results show that the compound is not a halide, and the water and methanol molecules are not coordinated with the calcium ion. Calcium(II) is eight-coordinated, binding to four sugar moieties via $\mathrm{O}(1), \mathrm{O}(2)$ of two molecules and $\mathrm{O}(3), \mathrm{O}(4)$ of the other two, with $\mathrm{O}(4)$ being deprotonated (Figure 3).

\section{Problems in Utilization of L-Arabinose}

L-arabinose monomers are rarely present in nature. It is difficult to separate L-arabinose crystal from L-arabinose-xylose liquor resulting in lower product yield and higher price, which limits the L-arabinose applications in various fields.

With the continuous promotion of L-arabinose used in food additives, health products, medicine, biotransformation and organic synthesis, L-arabinose demand and production is growing rapidly since 2002. The global L-arabinose production has increased fourfold, from the initial $375 \mathrm{t}$ to $9000 \mathrm{t}$, with an average annual growth rate of $30 \%$ during 2002 to 2014 . With the progress of L-arabinose isolation technology, the production costs and selling prices are further reduced. In 2014-2018, the global demand for L-arabinose stabilized at more than 8000 tons. Although the selling prices is reduced from 0.30 million Yuan/Ton of 2002 to 0.15 million Yuan/Ton of 2017, it is still too high for food fields or daily usage since it is 25 times higher than that of sucrose(about 6500 Yuan/Ton).

Unscientific consumption of L-arabinose can cause adverse reactions: excessive

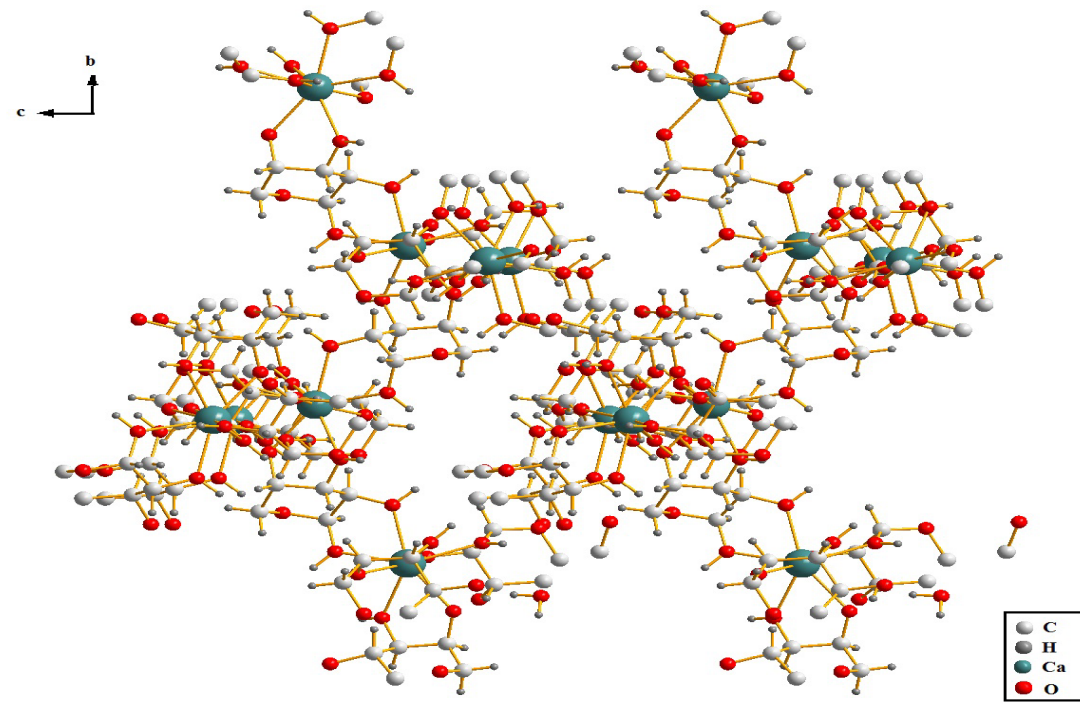

Figure 3. Molecular structure of calcium arabinose complexes. 
consumption of L-arabinose can cause abdominal distension, diarrhea and other intestinal disorders. This is because a large amount of carbohydrates, which is not digested and absorbed in the small intestine, enter the large intestine and promote the proliferation of beneficial bacteria (such as Bifidobacterium and acidophilus), resulting in excessive intestinal gas production. Therefore, patients with severe digestive and absorption disorders, intestinal inflammation, chronic intestinal diseases, partial intestinal obstruction, colonic ulcers, and flatulence are not suitable to use L-arabinose as food addictive.

\section{Conclusions}

Although L-arabinose demand and production is growing rapidly since 2002, most people don't know this new functional sweetener very much. It's urgent to increase the scientific propaganda and market promotion of L-arabinose. The $\mathrm{L}$-arabinose required for different purposes is different: dosage for auxiliary hypoglycemic is $3 \%-5 \%$ of the sucrose content; dosage for weight loss is $10-15$ grams TID; dosage for adjusting the intestinal flora is 3 - 5 grams TID. In order to achieve better results and avoid problems such as diarrhea and abdominal distension, it is recommended to take the prescribed dosage of L-arabinose before or during meals.

Although L-arabinose is widely exists in the nature, its relatively low in content and is difficult to separate from other monosaccharides which combine with L-arabinose to form hemicellulose. Acid hydrolysis of biomass contains alkaline extraction and acid hydrolysis of arabinoxylan, this method exists obvious drawbacks such as corrosion of equipment, potential of polluting the environment, and complex of procedures. Chemical synthesis or biotransformation method is not yet mature, since separation and purification of optical isomers remains the bottleneck of global industrial crystallization separation.

Research on enzyme hydrolysis of biomass to produce L-arabinose is the hotspot in recent years, a number of domestic and foreign companies have successfully developed the enzymatic production of L-arabinose, but production costs are still high since the activity of cellulase or arabinoxylanase is not high and the hydrolysis process is time consuming. However, Shandong Futase, Jinan Healtang use xylose mother liquor to produce L-arabinose, which significantly reduces the production costs. For now, the enzyme (microbial fermentation) is the most advanced technology in L-arabinose. To improve downstream industries (separation, purification and crystallization) of L-arabinose is the key in reducing manufacturing costs and increasing the production scale.

As an emerging healthy sugar, L-arabinose is expected to be widely used in household foods such as table sucrose, dairy products, cakes, bread, children's food, ice cream, beverages, desserts, and chocolate. The main factor that restricts the large-scale application of L-arabinose is that the price is too high, so the development of lower-cost L-arabinose syrup and L-arabinose-xylose syrup will effectively promote its application scope and scale. 


\section{Acknowledgements}

This project was supported by the National Natural Science Foundation of China Youth Science Foundation (81701171), Science and Technology Program of Guangdong (2017B030314123) and the Program of Guangdong Academy of Sciences (2016GDASPT-0108, 2017GDASCX-0105).

\section{Conflicts of Interest}

The authors declare no conflicts of interest regarding the publication of this paper.

\section{References}

[1] Agricultural Information Network of China (2018) Analysis of the National Sugar Supply and Demand Situation in March 2018. http://www.prcsiri.com/Article/Detail/2802

[2] Seri, K., Sanai, K., Matsuo, N., et al. (1996) L-Arabinose Selectively Inhibits Intestinal Sucrase in an Uncompetitive Manner and Suppresses Glycemic Response after Sucrose Ingestion in Animals. Metabolism: Clinical and Experimental, 45, 1368-1374. https://doi.org/10.1016/S0026-0495(96)90117-1

[3] Liu, X., Zhu, D., Sun, L., Gao, Y. and Wang, C. (2013) Effect of L-Arabinose on the Postprandial Blood Glucose and Body Weight. Journal of Hygiene Research, 42, 295-297.

[4] National Health and Family Planning Commission of the People's Republic of China (2008) Announcement of the Ministry of Health on Approving 7 Kinds of New Resource Foods Such As Lactobacillus Acidophilus (Announcement of the Ministry of Health No. 12 of 2008). http://www.moh.gov.cn/mohbgt/pw10807/200805/35651.html

[5] Breitner, J. (1962) Isolation of L-Arabinose from Agave Leaves. Journal of the Arizona Academy of Science, 2, 59-60. https://doi.org/10.2307/40025657

[6] Cheng, H.H., Wang, H.W. and Lv, J.Y. (2011) A Novel Method to Prepare L-Arabinose from Xylose Mother Liquor by Yeast-Mediated Biopurification. Microb Cell Fact, 10, 43-48. https://doi.org/10.1186/1475-2859-10-43

[7] Hu, B., Kai, H., Zhang, X.L., et al. (2015) Solubility and Seeded Metastable Zone Width of Functional Sugar L-Arabinose. Food Science \& Technology, 35, 51-57. https://doi.org/10.1590/1678-457X.6329

[8] Pingman, W. (1957) The Carbohydrates, Chemistry, Biochemistry, Physiology. Academic Press, New York, 79.

[9] Saulnier, L., Marot, C., Chanliaud, E. and Thibault, J.F. (1995) Cell Wall Polysaccharide Interactions in Maize Bran. Carbohydrate Polymers, 26, 279-287. https://doi.org/10.1016/0144-8617(95)00020-8

[10] Schols, H.A., Posthumus, M.A. and Voragen, A.G.J. (1990) Structural Features of Hairy Regions of Pectins Isolated from Apple Juice Produced by the Liquefaction Process. Carbohydrate Research, 206, 117-129. https://doi.org/10.1016/0008-6215(90)84011-I

[11] Karnik, D.A. (2012) Structure-Function Characterization of Fractionated Sugar Beet Pectin. The University of Georgia, Georgia.

[12] Loezacorte, J.M., Verdecalvo, J.R., Cruzsosa, F. and VernonCarter, E.J. (2007) L-Arabinose Production by Hidrolysis of Mesquite Gum by a Crude Extract with 
$\alpha$-L-Arabinofuranosidase Activity from Aspergillusniger. Revista Mexicana De Ingeniería Química, 6, 259-265.

[13] Wenbo, W., Fangong, K., Shoujuan, W. and Yajie, Z. (2013) Monosaccharides in Sulfuric Acid Hydrosate of Corn Stalk. Advanced Materials Research, 711, 173-177. https://doi.org/10.4028/www.scientific.net/AMR.711.173

[14] Kurakake, M., Kanbara, Y. and Murakami, Y. (2014) Characteristics of $\alpha$-L-Arabinofuranosidase from Streptomyces Sp I10-1 for Production of L-Arabinose from Corn Hull Arabinoxylan. Applied Biochemistry and Biotechnology, 172, 2650-2660. https://doi.org/10.1007/s12010-013-0691-3

[15] Kim, Y.S., Lim, Y.R. and Oh, D.K. (2012) L-Arabinose Production from Sugar Beet Arabinan by Immobilized Endo- and Exo-Arabinanases from Caldicellulosiruptor saccharolyticus in a Packed-Bed Reactor. Journal of Bioscience and Bioengineering, 113, 239-241. https://doi.org/10.1016/j.jbiosc.2011.10.008

[16] Liu, Q., Li, N. and Shen, Y. (2013) Selective Extration of L-Arabinose from Bagasse Pith with Hot Water Hydrolysis. Ieri Procedia, 5, 70-74. https://doi.org/10.1016/j.ieri.2013.11.072

[17] Zhang, P.Y., Zhang, Q. and Whistler, R.L. (2003) L-Arabinose Release from Arabinoxylan and Arabinogalactan under Potential Gastric Acidities. Cereal Chemistry, 80, 252-254. https://doi.org/10.1094/CCHEM.2003.80.3.252

[18] Ahmed, Z., Shimonishi, T., Bhuiyan, S.H., Utamura, M., Takada, G. and Izumori, K. (1999) Biochemical Preparation of L-Ribose and -L-Arabinose from Ribitol a New Approach. Journal of Bioscience \& Bioengineering, 88, 444-450.

https://doi.org/10.1016/S1389-1723(99)80225-4

[19] Semenza, G. and Von Balthazar, A. (1974) Steady-State Kinetics of Rabbit-Intestinal Sucrase. European Journal of Biochemistry, 41, 149-162. https://doi.org/10.1111/j.1432-1033.1974.tb03255.x

[20] Inoue, S., Sanai, K. and Seri, K. (2000) Effect of L-Arabinose on Blood Glucose Level after Ingestion of Sucrose-Containing Food in Human. Journal of the Japanese Society of Nutrition and Food Science, 53, 243-247. https://doi.org/10.4327/jsnfs.53.243

[21] Yao, X.F., Wang, X., Ying, Y., Wang, Z., Zhang, L.S. and Yang, Y.X. (2012) Inhibitory Effect of L-Arabinose on $\alpha$-Glucosidase Tested In Vitro. Chinese Journal of Food Hygiene, 4, 102-105.

[22] Sekime, A. and Akihir, F. (2004) Effect of Long Term Feeding of L-Arabinose in Genetically Obese Diabetic Rat. Digestion and Absorption, 26, 21-25.

[23] Li, K., Lu, X.L., Zhang, T.T. and Wang, T.T. (2013) Effect of L-Arabinose on Glucolipid Metabolism in Metabolic Syndrome Rats. Chinese Food Additives, No. 4, 116-119.

[24] Han, W., Wu, H.Z. and Yang, C.X. (2009) Effect of L-Arabinose on Decreasing Fat Index in Obese Rabbits Caused by High Glucose and High Fat. Chinese Journal of Medicinal Guide, 11, 1528-1530.

[25] Shibanuma, K., Degawa, Y. and Houda, K. (2011) Determination of the Transient Period of the EIS Complex and Investigation of the Suppression of Blood Glucose Levels by L-Arabinose in Healthy Adults. European Journal of Nutrition, 50, 447-453. https://doi.org/10.1007/s00394-010-0154-3

[26] Nyman, M., Asp, N.G. and Cummings, J. (1986) Fermentation of Dietary Fibre in the Intestinal Tract: Comparison between Man and Rat. The British Journal of $\mathrm{Nu}$ trition, 55, 487-496. https://doi.org/10.1079/BJN19860056 
[27] Long, R.T., Zeng, W.S., Chen, L.Y., et al. (2010) Bifidobacterium as an Oral Delivery Carrier of Oxyntomodulin for Obesity Therapy: Inhibitory Effects on Food Intake and Body Weight in Overweight Mice. International Journal of Obesity, 34, 712-719. https://doi.org/10.1038/ijo.2009.277

[28] Ayumi, K., Noriko, T. and Mineko, I. (2005) Effects of L-Arabinose on Skeletal Muscle Fiber Composition. Journal of the Japanese Society of Nutrition and Food Science, 58, 51-57. https://doi.org/10.4327/jsnfs.58.51

[29] Wang, X., Yao, X., Ying, Y., et al. (2012) Effect of L-Arabinose on Glucose and Lipid Metabolism in Type 2 Diabetic Rats. Wei Sheng Yan Jiu, 41, 260-263, 267.

[30] Zhu, D.C., Lv, Z.F., Liu, X.R., et al. (2011) Advance Research on the Application of L-Arabinose. Food and Fermentation Industries, 37, 125-129.

[31] Yoon, H., Kim, C.H., Kim, T., Han, K.I. and Soo, N. (2003) Novel Functional Sugar L-Arabinose: Its Functionality, Uses and Production Method. Korean Journal of Food Science and Technology, 5, 757-763.

[32] Wang, C.F., Tian, Q., Wang, Q.Y., et al. A New Type of Functional Healthy Sugar and Preparation Process. CN101897420A.

[33] Tang, Y.L., Jiang, C.Z., Ding, J.W., et al. L-Arabinose as an Anti-Alcoholic Health Care Product. CN101797023A.

[34] Kunihisa, F. Beverage Containing L-Arabinose. JP2000357395.

[35] Ye, W.B. A Herbal Tea Containing L-Arabinose. CN102987028A.

[36] Hou, Y.L. (2010) Thermal Properties of Maillard Reaction on L-Arabinose/ L-Cysteine Model System. Journal of Food Science and Biotechnology, No. 1, 71-76.

[37] Wang, X. (2012) Application of L-Arabinose in Chocolate and Cake. Agricultural Products Processing (Innovation), No. 2, 60.

[38] Helanto, M., Kiviharju, K., Granstrom, T., Leisola, M. and Nyyssola, A. (2009) Biotechnological Production of L-Ribose from L-Arabinose. Applied Microbiology and Biotechnology, 83, 77-83. https://doi.org/10.1007/s00253-008-1855-x

[39] Zhang, H., Jiang, B. and Pan, B. (2007) Purification and Characterization of L-Arabinose Isomerase from Lactobacillus Plantarum Producing D-Tagatose. World Journal of Microbiology and Biotechnology, 23, 641-646. https://doi.org/10.1007/s11274-006-9274-6

[40] El-Farargy, A.F. and Ghonium, A.A. (2008) Synthesis of Some New C-Nucleosides from L-Arabinose and D-Glucose. Arkivoc, No. 13, 278-285.

[41] Jeong, J.H., Kim, K., Lim, D., et al. (2014) Anti-Tumoral Effect of the Mitochondrial Target Domain of Noxa Delivered by an Engineered Salmonella Typhimurium. Plos One, 9, E80050. https://doi.org/10.1371/journal.pone.0080050

[42] Li, X., Wang, Y., Han, D., et al. (2013) Correlation of Hepatitis B Surface Antigen Level with Response to Telbivudine in Naive Patients with Chronic Hepatitis B. Hepatology Research, 44, 25-29.

[43] Kaluzhny, D.N., Tatarskiy, V.V., Dezhenkova, L.G., et al. (2009) Novel Antitumor L-Arabinose Derivative of Indolocarbazole with High Affinity to DNA. Chemmedchem, 4, 1641-1648. https://doi.org/10.1002/cmdc.200900227

[44] Zhang, M. A L-Arabinose Fermenting Yeast. CN 20120129241.

[45] Boles, E. Vector with Codon-Optimised Genes for an Arabinose Metabolic Pathway for Arabinose Conversion in Yeast for Ethanol Production. US 20140206070.

[46] Bouquillon, S. (2011) D-Xylose and, L-Arabinose-Based Surfactants: Synthesis, Reactivity and Physico-Chemical Properties. Comptesrendus-Chimie, 14, 716-725. 
https://doi.org/10.1016/j.crci.2010.06.016

[47] Hu, B., Yu, D., Huang, K., et al. (2015) Metal-Ion Interactions with Sugars: Crystal Structure of Bis(4-dehydro-L-arabinose) Calcium Methanol Bishydrate. Chinese Journal of Structural Chemistry, 34, 764-770. 